\title{
Conquistas e perdas dos atingidos pela Usina de Salto Caxias: o caso da comunidade Nova Uniáo em Cascavel (PR)
}

Emerso Cristani da Cunha ${ }^{1}$ João Edmilson Fabrini²

\begin{abstract}
Resumo
Vivemos em um período de constantes transformações mundiais, que requerem um aparato de recursos, naturais e humanos, intensos. Essas transformações, às vezes, impactam diretamente em grupos, povos, ou seja, acabam, de alguma forma, provocando transtornos, desde os mais simples aos mais complexos. A construção de uma usina hidrelétrica provoca mudanças nos aspectos geográfico, econômico e social da região onde ocorre. Em Salto Caxias, não foi diferente. Várias famílias foram retiradas de suas casas, tendo, com isso, que buscar outros caminhos em novas terras. Essas pessoas organizaram-se e formaram um movimento social, a Crabi, que se tornou uma importante ferramenta de enfrentamento e conseguiu muitas conquistas para os envolvidos. Essas conquistas foram a terra, a infraestrutura, o aprendizado político e a ajuda mútua. As perdas foram as dos laços de amizade e parentesco, da ligação com a terra onde moravam, das práticas agrícolas convencionais e o rompimento de relações com o comércio local. Portanto, houve conquistas e perdas, pois o processo é contraditório.
\end{abstract}

Palavras-chave: Movimento Social. Conquistas. Reassentamento.

\begin{abstract}
We live in a period of constant global transformations that require an apparatus of resources, natural and human, intense. These changes directly impact sometimes in groups, people, or just somehow causing disorders, from simple to more complex. The construction of a hydroelectric plant causes changes in geographic, economic and social aspects of the region where it occurs. Salto Caxias was no different. Several families were evacuated from their homes, taking with it, to seek other paths in new lands. These people organized themselves and formed a social movement, krabi, which became an important coping tool and got many achievements for those involved. These achievements were the land, infrastructure, political learning and mutual aid. Losses were ties of friendship and kinship, connection to the land where they lived, conventional agricultural practices, and broken relationships with local businesses. Therefore, there were gains and losses since the process is adversarial.
\end{abstract}

Keywords: Social Movement. Achievements. Resettlement.

\footnotetext{
${ }^{1}$ Mestre em Desenvolvimento Rural Sustentável. Professor da Universidade Estadual do Oeste do Paraná (UNIOESTE). emerso.c.cunha@gmail.com

2 Doutor e Pós-doutor em Geografia. Professor da Universidade Federal da Grande Dourados (UFGD). joaofabrini@gmail.com
} 


\section{Introdução}

O processo de industrialização e os avanços, em diversos setores da economia do Brasil, demandam a produção de energia. A exploração dos potenciais hidráulicos do Brasil, nos últimos 40 anos, está inserida nesse contexto.

O Brasil tem explorado seu potencial energético, principalmente se valendo de seus recursos naturais, dentre os quais destaca-se o grande potencial hidrográfico. Assim, o Brasil tem apostado em energia barata, renovável a longo prazo e com recursos próprios.

Esse modelo energético pode ser representado por um megaprojeto de represamento das águas, como foi o caso da Itaipu. Essa barragem é famosa pelo gigantismo e aplicação da engenharia moderna, porém sua construção, tida como modelo de geração de energia, provocou inúmeros transtornos aos pequenos agricultores pela dimensão dos seus reservatórios e, por ocasião disso, fez com que inúmeras famílias fossem deslocadas involuntariamente do seu território. Para Ribeiro (2002, p. 23), "além do gigantismo físico da obra, gigantescos foram também os problemas sociais causados [...]". Ribeiro (2002, p. 25) ainda enfatiza que:

A Itaipu foi construída durante os anos do 'Milagre Econômico Brasileiro' que caracterizou o Brasil pós-1964, período no qual foi imposto um governo que pôs em prática grandes projetos de investimento econômico, cuja meta foi a de implantar aqui uma indústria forte de bens de capital.

Outras barragens, nem tão expressivas como Itaipu, são construídas no Brasil, impulsionadas pela necessidade de geração de energia, para atender a demanda do capital industrial existente, e vêm provocando deslocamentos populacionais involuntários.

A Usina Hidrelétrica Salto Caxias, construída no Rio Iguaçu, entre os municípios de Capitão Leônidas Marques e Nova Prata do Iguaçu, no Sudoeste do Paraná, é outro exemplo de construção de barragem para a produção de energia. Encabeçada pela empresa estatal Companhia Paranaense de Energia Elétrica - Copel (2014) - essa usina hidrelétrica provocou o deslocamento de aproximadamente 1322 famílias nas regiões Oeste e Sudoeste do Paraná, na década de 1990.

Esses atingidos formaram um movimento social chamado Comissão Regional de Atingidos por Barragens do Iguaçu - Crabi - que, na oportunidade, se legitimou para conduzir as negociações com a companhia - Copel. A Comissão representava os proprietários rurais, os posseiros e os arrendatários dos terrenos atingidos pela formação do reservatório da usina hidrelétrica Salto Caxias.

As famílias conseguiram ser indenizadas seguindo critérios acordados entre a empresa responsável pela obra e a Crabi, sendo que os proprietários com terrenos iguais ou maiores que cinco alqueires paulistas $\left(24.200 \mathrm{~m}^{2}\right.$ ) eram pagos através de uma carta de crédito, enquanto que proprietários de terras com até cinco alqueires, arrendatários e posseiros tinham opção de escolha entre carta de crédito ou reassentamento em terrenos escolhidos pelo movimento social, na região Oeste e Sudoeste do Paraná.

A Crabi conduziu todas as negociações, representando os atingidos, e teve participação decisiva na aquisição de terras e organização dos reassentamentos. Mesmo após a sua dissolução, na prática, em meados da década de 2000, a Comissão continuou 
representando a luta dos atingidos, sendo objeto de vários estudos, por tratar-se de um movimento social que conseguiu importantes conquistas para os atingidos de Salto Caxias.

Nesse sentido, a problemática desta pesquisa salienta a postura do movimento social Crabi enquanto organização, para a busca de melhorias em prol dos atingidos de Salto Caxias, nas negociações com a Copel. Nos critérios de indenizações, assegurados através das lutas e ocupações que este movimento realizou, ficou muito evidente a participação deste.

Assim, esta pesquisa tratará das conquistas dos atingidos, em especial da comunidade Nova União, formada a partir do reassentamento dessas famílias. Evidenciará também as perdas derivadas da expulsão das famílias da terra com a formação do lago da usina de Salto Caxias.

Nossa hipótese é que houve conquistas e perdas dos atingidos por Salto Caxias, e que as conquistas, principalmente, muito se devem à criação e ao contexto de lutas desencadeadas pela Crabi, permitindo aos atingidos se manterem na atividade rural, uma vez que era essa sua atividade econômica. Essa hipótese se justifica, uma vez que, em situações de desapropriação, ocorrem perdas significativas para os atingidos, enquanto que os de Nova União parecem estar satisfeitos com o processo indenizatório.

Será enfatizada a comunidade Nova União, situada nas antigas instalações da Fazenda Flamapec, hoje Colônia São Francisco de Assis, em Cascavel. Além da luta organizada em torno da Crabi, ela também teve importância e influência nas práticas agrícolas dos reassentados.

A escolha de Nova União, para enfatizar as conquistas no contexto de perdas, foi motivada por tratar-se de famílias vindas de uma mesma região do município de Nova Prata do Iguaçu, mais precisamente das comunidades Fazendinha e Barra do Vorá. Foi desse município o terceiro maior grupo de famílias atingidas pela formação do lago de Salto Caxias, num total de 326 (trezentos e vinte e seis) famílias. Considerando que uma das lutas do movimento era a manutenção das características das comunidades anteriores, a comunidade Nova União se organizou levando em conta as da vizinhança.

As conquistas desses atingidos, baseadas nas reivindicações do movimento Crabi, apresentavam características únicas no quesito indenizações. Essas conquistas foram, inicialmente, a terra, pois o reassentamento foi conquistado apenas para os arrendatários e para pessoas que possuíam até cinco alqueires paulistas, passando por uma quantia em dinheiro, no valor de um salário mínimo por casal, durante o período de um ano. Conquistaram também a infraestrutura organizada, tanto na propriedade como na comunidade, para que os moradores de Nova União pudessem dar continuidade às suas vidas.

Buscou-se ainda identificar conquistas políticas resultantes do movimento, através das reuniões que a comunidade organizava, dos encontros de famílias e das festas que são realizadas para confraternização com a comunidade externa à Nova União. Verificaram-se também as conquistas em termos de Educação, com a construção de escola, para uso exclusivo dos reassentados, na sede do reassentamento São Francisco de Assis, e, ainda, conquistas em termos de "valorização" da terra, por tratar-se de uma região onde os terrenos possuem preço elevado. 


\section{Metodologia da pesquisa}

Nesta pesquisa, foram entrevistadas 16 (dezesseis) famílias moradoras da comunidade de Nova União, que correspondem a $40 \%$ dos seus moradores. 0 critério de escolha dos entrevistados da comunidade foi o de selecionar aqueles que estão na comunidade Nova União desde a sua formação inicial, pois estiveram envolvidos no processo de saída de suas terras e escolha das novas propriedades, ou seja, que efetivamente estiveram envolvidos no processo de lutas pela terra.

As entrevistas foram realizadas em maio de 2014, na propriedade de cada morador entrevistado, com o intuito de deixá-lo mais à vontade e, com isso, conseguir o máximo de informações pertinentes à pesquisa. Durante as entrevistas, participaram basicamente o casal, com respostas frequentemente dadas pelo homem.

A realização da entrevista na propriedade do entrevistado buscou também verificar in loco as condições de moradia e equipamentos utilizados no processo produtivo da propriedade, uma vez que a pesquisa avaliou conquistas e perdas desses moradores.

As informações foram coletadas por meio de entrevistas aos reassentados da comunidade Nova União, sendo esses visitados pelo autor em horários que variaram entre manhã, tarde e noite, de acordo com a atividade de cada entrevistado. Os horários alternativos deram-se devido ao fato de vários entrevistados estarem ligados à produção de leite, e seus horários disponíveis restringirem-se, no período da manhã, das nove horas e trinta minutos ao meio dia e, no da tarde, das treze e trinta às dezesseis horas. Ocorreram casos em que as entrevistas foram realizadas à noite, por facilitar o diálogo e a coleta de informações do entrevistado.

As entrevistas tiveram caráter qualitativo e quantitativo, seguindo um roteiro de perguntas, porém deixando o entrevistado totalmente à vontade para responder e discorrer sobre assuntos que envolveram desde as primeiras reuniões, antes da formação do lago, até a situação atual do entrevistado. Esse critério de pesquisa aproximou pesquisador e pesquisado, enriquecendo o conteúdo das respostas. Para preservar a identidade dos entrevistados, utilizamos a letra " $\mathrm{P}$ " (propriedade) maiúscula e os números $(1,2,3,4,16)$, de acordo com a ordem das entrevistas, para referenciar os depoimentos.

Para entender a construção da barragem e as conquistas dos atingidos por Salto Caxias, considera-se pertinente compreender o contexto e o período histórico em que elas estão inseridas.

\section{Copel e as usinas hidrelétricas no Rio Iguaçu}

No Estado do Paraná, encontra-se um importante rio que corta o seu território de Leste a Oeste e representa a história do povo paranaense, o Rio Iguaçu, conforme destaca uma série especial da Gazeta do Povo em 2010. Nesta série, o jornalista João Rodrigo Maroni destaca que "Tudo que diz respeito ao Iguaçu ganha sempre proporções majestosas: da capacidade de geração de energia à exuberância de suas paisagens". Além disso, Maroni (2014) destaca que: 
Ao longo da história do estado, o Rio Iguaçu se transformou em testemunha do surgimento da cultura e da sociedade paranaense. Viu, por exemplo, o desbravador espanhol Cabeza de Vaca chegar às Cataratas em 1542 e acompanhou de perto o ciclo da erva-mate e da madeira nos séculos 19 e 20, quando os velhos vapores subiam e desciam o rio integrando cidades e fortalecendo a economia.

O Rio Iguaçu nasce na região de Curitiba e desemboca no Rio Paraná, em Foz do Iguaçu, e, pelo caminho, deixa um rastro que se confunde entre beleza e degradação, alimentando cinco usinas hidrelétricas em funcionamento e atendendo quase $30 \%$ da demanda de água do estado do Paraná.

\section{Figura 1- Usinas Hidrelétricas no Estado do Paraná}

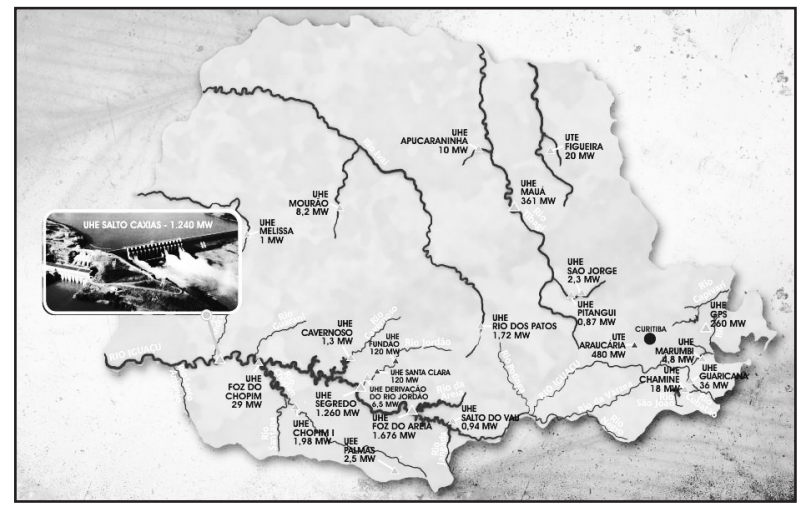

Fonte: Copel (2014)

Na Figura 1, verifica-se o percurso do rio Iguaçu, desde sua nascente até sua foz, banhando várias regiões mais no sul do Estado, tendo sobre esse rio a construção de usinas hidrelétricas controladas pela Copel.

As usinas hidrelétricas atualmente (COPEL, 2014) em funcionamento no rio Iguaçu são comandadas pela Copel, segundo informa o site da empresa. A criação da empresa fez parte do plano de eletrificação do Paraná, conforme o histórico disponível em seu site.

$\mathrm{Na}$ agenda destes empreendimentos hidrelétricos, o represamento das águas do Rio Iguaçu foi e continua sendo destaque. As usinas hidrelétricas construídas neste rio são as seguintes: Salto Grande do Iguaçu, em 1967; Foz do Chopin, em 1970; CapivariCachoeira, em 1971; Foz do Areia, em 1980; Usina de Segredo, em 1990, e Usina Salto Caxias, em 1999 (uma das mais importantes da Copel, com capacidade de 1.240 MW de potência). 
Figura 2 - Usinas hidrelétricas sobre o rio Iguaçu

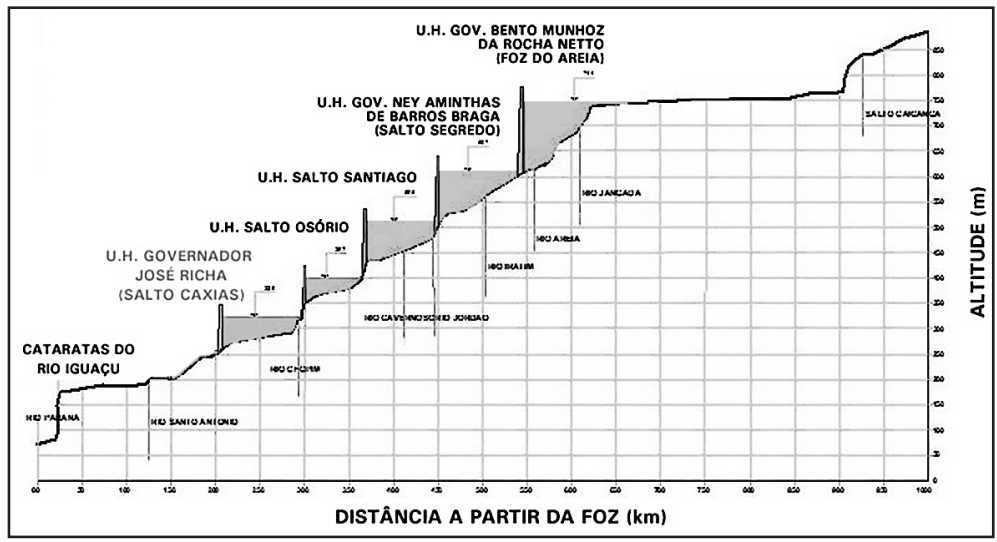

Fonte: Copel (2014).

Todos esses empreendimentos realizados no Rio Iguaçu provocaram mudanças nos aspectos econômico, ambiental, social e político das regiões, conforme descreve Derrosso e Ichikawa (2013, p. 134), quando diz que "problemas ambientais e sociais começam a surgir, pois uma importante área de terra (na maioria das vezes, produtiva) será alagada e todo sistema social e ecológico será destruído para sempre". Com isso, as famílias atingidas pela formação dos reservatórios de água das hidrelétricas precisam ser remanejadas, ainda que contra a vontade, dentro do próprio município (quando possível), ou para outros municípios e regiões.

Esse remanejamento levou os atingidos de Salto Caxias a se organizarem para enfrentarem a realidade imposta pela empresa responsável pela realização da obra. Esse enfrentamento colocou em pauta os interesses entre as pessoas atingidas direta ou indiretamente e os responsáveis pela construção, desdobrando-se no surgimento do movimento social Crabi.

\section{0 movimento de atingidos por barragens no Brasil}

Segundo Scherer-Warren (2008), o Movimento de Atingidos por Barragens aumentou gradativamente na década de 1970, juntamente com outros movimentos emergentes no Brasil, mediados principalmente pela CPT (Comissão Pastoral da Terra). Em 1991, em Brasília, foi realizado o I Congresso Nacional de Atingidos por Barragens, quando se consolidou o MAB - Movimento de Atingidos por Barragens, em escala nacional.

$O$ MAB surgiu a partir dos focos de resistência e oposição à construção de barragens em todo o Brasil, e sua luta preconizava desde o impedimento das obras, a adequação dos projetos e, principalmente, a indenização de forma justa aos atingidos por construções desta natureza.

A presença do MAB, hoje, nas negociações com as empresas e outros atores responsáveis pelas obras de hidrelétricas, é uma constante e pode ser verificada tanto in loco como pelas redes sociais, nas quais o movimento mantém publicações sobre as 
várias frentes de atuação em todo o Brasil.

Outra luta do MAB é a discussão da falta de energia, que, no entendimento do Movimento, trata-se de um alarmismo da mídia corporativa, do governo e dos investidores. Segundo o Movimento, existe um interesse, principalmente das grandes corporações, de que haja excedente de energia para que esta seja adquirida de forma mais barata.

Estudiosos da questão energética do movimento garantem que se trata de uma "falácia", baseados em dados da própria Agência Nacional de Energia Elétrica (ANEEL) e do Ministério das Minas e Energia (MME). Gonçalves Júnior, em MAB (2008, p. 71), professor de engenharia elétrica da Universidade Federal do Mato Grosso (UFMT), assegura que esse risco não confere e, principalmente, que atualmente, com o sistema interligado de energia elétrica, temos uma Itaipu de stand by.

Rosa, da COPPE/UFRJ e ex-presidente da Eletrobrás, em Textos de aprofundamentos e debate - MAB (2008, p. 71), diz que "existe um grupo de privilegiados chamados de consumidores livres que consomem $30 \%$ da energia do Brasil a um preço baratinho. Quem paga é o pobre".

Dom Orlando Dotti, bispo Emérito da Diocese de Vacaria/RS e grande apoiador do MAB, em MAB (2008, p. 73), diz que "antes de produzir energia, as hidrelétricas produzem excluídos". Segundo Dom Orlando, esse pensamento não é só dele, e sim de toda a igreja. E acrescenta (2008, p. 73):

A opressão aos atingidos acontece porque existe uma promiscuidade entre as empresas, o ministério público e o judiciário. Uma promiscuidade que dita o que se deve fazer para que a barragem seja construída e para o lucro das empresas, não se importando com o que acontece com o povo.

O MAB relata, em vários trechos do caderno pedagógico "Textos, aprofundamentos e debates de 2008", que as forças foram intensificadas contra os movimentos e seus apoiadores durante as tentativas do movimento de impedir as construções de hidrelétricas pelo Brasil. Os processos de despejo das famílias e reintegração de posses têm sido feitos usando a polícia local e até a polícia federal. Além disso, em Tucuruí (PA), no mês de março de 2005, até o exército, com poder de polícia, foi usado para fazer guarda à construção da hidrelétrica. Relata ainda que, em outubro de 2005 , "50 policiais invadiram e destruíram completamente um acampamento de agricultores próximo ao Rio Canoas, na região atingida pela barragem de Campos Novos, em Santa Catarina" (MAB, 2008 , p. 74). Ou seja, as pessoas que estão sendo atingidas, como se não bastasse a expulsão, ainda estão sendo tratadas como criminosas.

Recentemente, o MAB fez denúncia contra a violação dos direitos humanos das pessoas atingidas por barragens. Nessas denúncias apresentadas ao Conselho de Defesa dos Direitos da Pessoa Humana (CDDPH), órgão ligado à Secretaria Especial de Direitos Humanos (SEDH) da União, são apontadas violações do tipo comunidades esquecidas e isoladas, repressão policial, direitos negados ou não reconhecidos e tradições culturais extintas. Um defensor público da União, João Paulo Dorini, da Comissão Especial, montada para investigar as denúncias, confirmou todas as denúncias feitas pelo MAB. Segundo esse defensor, em Acuã, na Paraíba, "os moradores saíram de suas casas com a água pelos pés e hoje estão absolutamente esquecidos" (MAB, 2008, p. 77). 
O movimento denuncia, em vários trechos de seu caderno pedagógico de 2008 , que a energia elétrica no Brasil tem estado a serviço das grandes corporações internacionais que não são viáveis em seus países e que, aqui, no Brasil, acabam tornando-se viáveis devido ao baixo custo de energia e incentivos governamentais produzidos às custas do povo brasileiro.

Todas essas reivindicações, denúncias e alertas fazem com que o MAB seja atualmente um movimento de respeito e de incessantes lutas contra a construção das hidrelétricas. O movimento enfatiza que se deve realizar busca por energia de outras maneiras menos prejudiciais ao meio ambiente e principalmente à vida humana.

Nessa linha de raciocínio, é que surge um importante movimento que mistura busca por direitos, solidariedade e força, o qual, mesmo com vários fatores contrários, ainda que não tenha conseguido evitar essas construções, fez com que as pessoas atingidas fossem vistas, e, principalmente, que suas necessidades básicas fossem atendidas, fazendo com que o transtorno dos pequenos agricultores de deixarem suas terras pudesse ser amenizado. Nesse contexto de luta entre a construção de Hidrelétricas e atingidos por barragens, organizados no MAB, é que surgiu a Crabi - Comissão de Atingidos por Barragens do Iguaçu.

\section{A Crabi: um movimento forte}

O início do que futuramente seria a Crabi ocorreu em uma reunião em Francisco Beltrão, com a participação dos membros do Sindicato dos Trabalhadores Rurais dos municípios que teriam famílias atingidas pela construção da barragem. A reunião também teve participação do Movimento de Atingidos por Barragens (MAB), Comissão Pastoral da Terra (CPT), Comissão Regional de Atingidos por Barragens no Rio Grande do Sul (CRAB/RS) e da Associação de Estudos, Orientação e Assistência Rural (ASSESSOAR).

Nessa reunião, em vista da iminência da construção da futura hidrelétrica de Salto Caxias, os representantes dos "futuros" atingidos começaram as mobilizações, principalmente por saberem através do MAB e CPT que, caso não se organizassem, teriam dificuldades de ser indenizados.

Nas falas dos entrevistados, como o atingido P14, que diz: "Vim do Rio Grande do Sul pra Nova Prata do Iguaçu e achava que nunca sairia de lá, mas, quando fiquei sabendo da barragem, fiquei com medo de perder minhas terras e minha família ficar sem nada". Nesse depoimento, não são encontrados relatos de oposição à construção da barragem, o que se percebe é que os atingidos estavam preocupados com o não recebimento de indenizações de suas terras.

Após esse início das mobilizações, as comunidades elegeram representantes para formar um grupo principal, capaz de representar todos nas negociações com a construtora da barragem. Foi eleita uma diretoria composta por José U. Camilo, Hélio Bruning e Margarete Maran. Surgiu então a Comissão de Atingidos por Barragens do Iguaçu (Crabi), com a incumbência de não deixar acontecerem os mesmos problemas que ocorreram com a construção de outras barragens realizadas pela Copel. 


\section{Resultados e discussões}

A pesquisa realizada com a comunidade Nova União buscou caracterizar as conquistas que ocorreram no contexto de perdas resultantes das desapropriações para a construção de uma usina hidrelétrica. Nesse sentido, descrevemos as conquistas e perdas baseados nas percepções do que foi relatado pelos entrevistados.

Como conquistas, consideramos as mudanças referentes à infraestrutura, terra, aprendizagem de organização e luta, proximidade a centros de referência em atendimento de saúde e proximidade com centro comercial (facilitador de venda da produção).

Como perdas, foram considerados os laços de afetividade desfeitos ou dificultados pela mudança abrupta para outra localidade, pois não foram todos os da antiga comunidade que foram atingidos. Consideramos ainda, como perdas, os aspectos naturais (paisagem, clima), a relação construída no comércio do antigo município, que precisou ser refeito na nova cidade, e reconstrução da propriedade (arborização, preparo da terra e readaptação).

Figura 3 - Condição de posse das terras pelos atingidos entrevistados

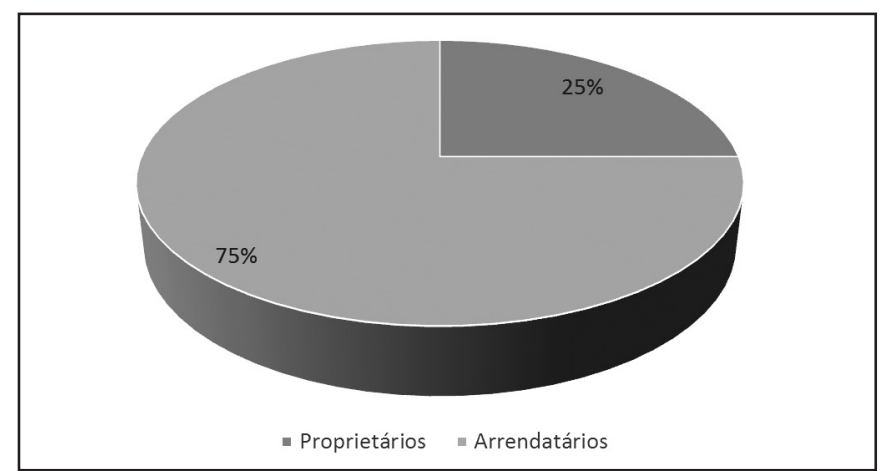

Fonte: Pesquisa de campo (2014).

Ao avaliarmos o quesito terra, podemos verificar que a maioria dos reassentados de Nova União eram arrendatários, ou seja, não possuíam suas próprias terras.

Mesmo os proprietários eram pessoas que possuíam terrenos inferiores a cinco alqueires paulistas ( $24.200 \mathrm{~m}^{2}$ de área), e, por esse motivo, dada a diferença de valorização do terreno da Região Oeste, terreno este com elevado preço de mercado, segundo estimativa dos reassentados, houve um ganho em termos de preço dos terrenos, pois, em comparação com os terrenos da Região Sudoeste, onde viviam, esses terrenos, com características semelhantes aos das antigas propriedades dos reassentados, apresentam valor entre cinquenta e sessenta mil reais (2014), ou seja, têm um preço em torno de $50 \%$ a mais do que os da antiga propriedade.

As conquistas para os moradores de Nova União não ocorreram do dia para a noite. Foram resultado de muita luta e organização durante quase dez anos, desde as primeiras notícias da construção da futura usina, até as indenizações e organizações nos reassentamentos escolhidos pela Crabi e comprados pela Copel. 
Como visto antes, os atingidos precisaram organizar várias manifestações em frente ao Palácio Iguaçu, sede do governo paranaense, e também no canteiro de obras da usina em Salto Caxias.

Essa demonstração de mobilização tem reflexos nas conquistas dos atingidos, deixando evidente que não houve doação por parte da Copel, e, sim, foram conquistas arrancadas com as lutas e enfrentamentos. Podemos verificar, então, que a terra foi uma conquista importante para os atingidos, e que não ocorreu apenas sob o ponto de vista dos arrendatários que não possuíam terra alguma, mas também dos pequenos proprietários que, além de aumentarem a área que possuíam anteriormente, acabaram ainda conseguindo valorizar essa área, pelos aspectos regional e geográfico do terreno, que permitem o desenvolvimento de uma gama maior de atividades.

Para comparar o preço das terras, descritas pelos reassentados como de preço maior que as terras de Nova Prata do Iguaçu, realizamos levantamento do preço definido pela Secretaria de Agricultura e Abastecimento (SEAB).

Esses dados secundários foram obtidos de uma planilha na qual a SEAB divulga o preço por município, de acordo com a classificação da terra. Usamos, para a elaboração de um comparativo, dois tipos de classificação: terra mecanizada e terra mecanizável de Cascavel e Nova Prata do Iguaçu.

\section{Figura 4 - Gráfico comparativo entre Cascavel e Nova Prata do Iguaçu quanto ao preço da terra por hectare $\left(10.000 \mathrm{~m}^{2}\right)$}

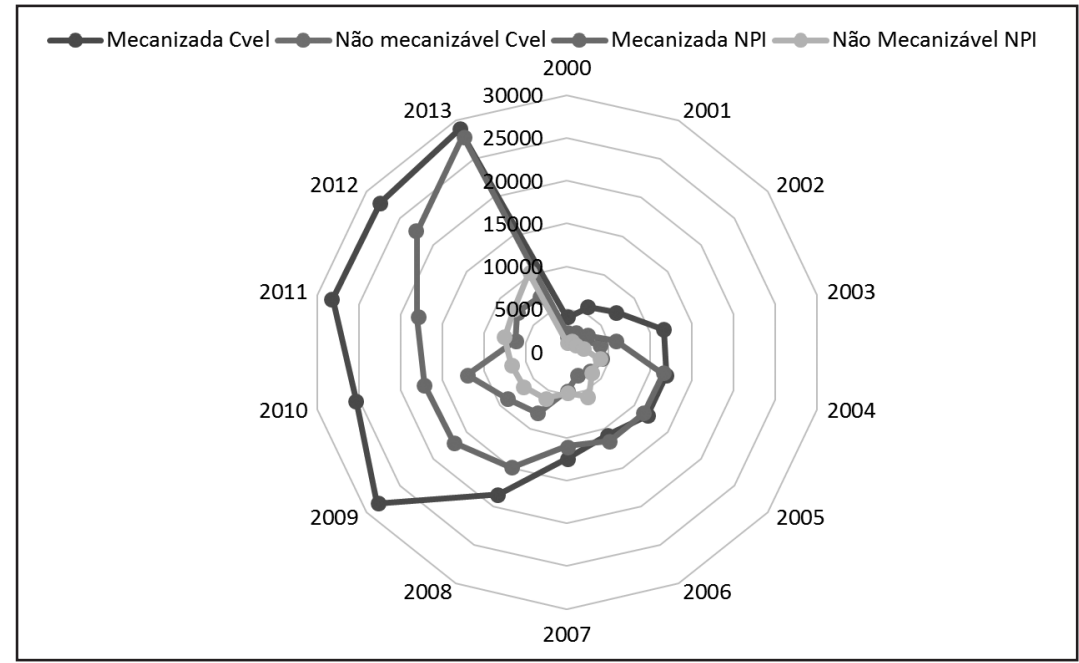

Fonte: Elaborada pelos autores a partir de dados da SEAB/DERAL (2014).

A partir da análise gráfica, verifica-se que o preço das terras entre os dois municípios apresenta disparidades. Além disso, ao somarmos os preços das terras mecanizáveis com os preços das terras não mecanizáveis, essa diferença torna-se ainda maior, prevalecendo o que disseram os reassentados quando apontaram as terras de Cascavel com preços maiores que as de Nova Prata. 
A terra, porém, não foi a única conquista dos reassentados. A infraestrutura na propriedade, composta por barracão de alvenaria, a água de poço artesiano, a construção de um núcleo para a comunidade Nova União (igreja, salão comunitário, quadra de esportes e campo de grama), além de colégio (fundamental e médio) para uso dos reassentados, conseguido através de parceria com o governo do estado, são exemplos de outras conquistas adquiridas com as lutas da Crabi frente à Copel. Quanto às atividades que desenvolviam no lote de terra, antes de serem atingidos pela usina, os dados são os seguintes:

Figura 5 - Atividades realizadas nas propriedades antes do reassentamento

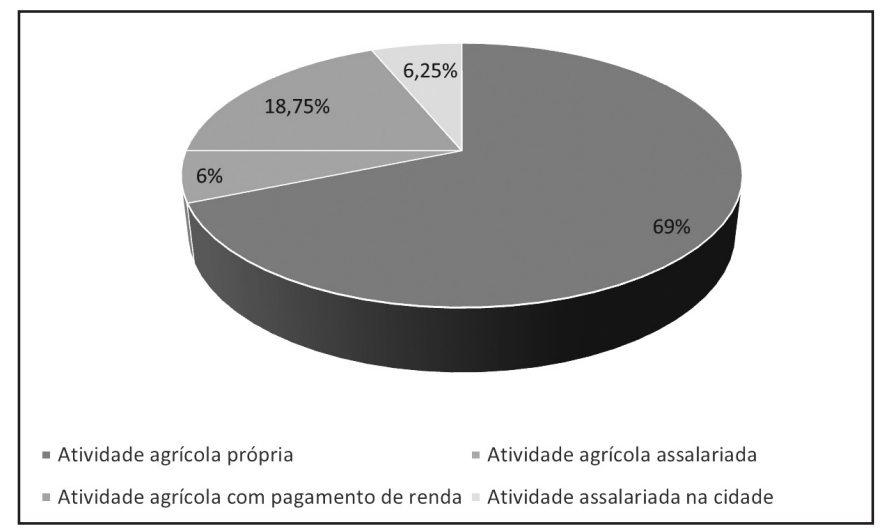

Fonte: Pesquisa de campo (2014).

Os entrevistados que não eram proprietários nem pagavam renda relataram que proprietários de terra, na antiga comunidade, cediam pequenas frações dessas terras para que eles pudessem plantar pequenas quantidades, suficientes para alavancar, mesmo que de forma precária, o sustento de suas famílias. Relatam ainda que essa atividade foi o que Ihes garantiu participar do cadastro feito pela Copel, após pressões do movimento e, consequentemente, ter direito ao reassentamento ou à carta de crédito.

O reflexo disso aparece nos resultados das entrevistas, quando os reassentados são questionados sobre as conquistas. A resposta com maior frequência é a da conquista da terra, e a de segunda maior frequência é a da infraestrutura da propriedade.

Os reassentados informaram que "escolheram" o reassentamento em Cascavel, uma vez que poderiam optar pela "carta de crédito" ${ }^{3}$, ou ainda outros reassentamentos, inclusive no próprio município.

\footnotetext{
${ }^{3}$ A carta de crédito era um valor que o atingido teria à disposição caso não quisesse ir para um reassentamento. O valor para os arrendatários era de trinta e cinco mil reais (valores da época) e, para os proprietários, sofria variação para mais, conforme a área e as benfeitorias da propriedade.
} 


\section{Figura 6 - Motivo da “opção" pelo reassentamento em Cascavel}

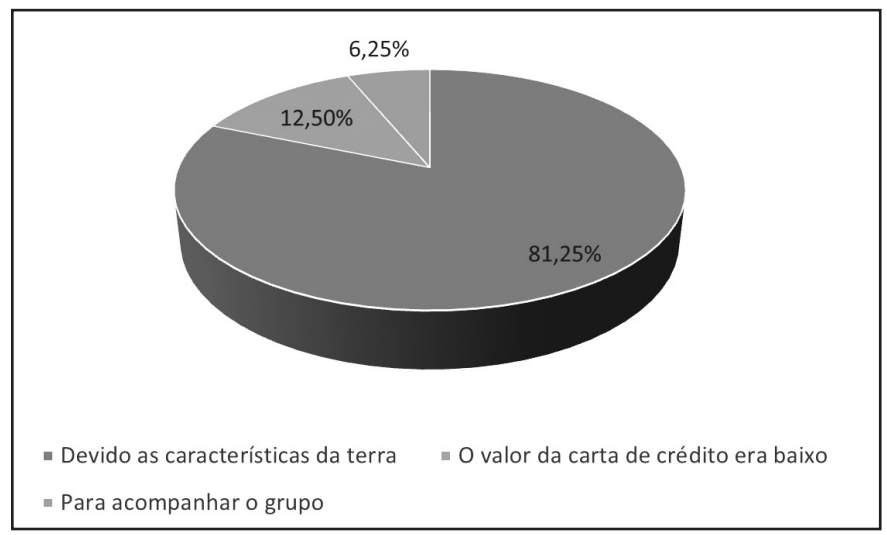

Fonte: Pesquisa de campo (2014).

Para os agricultores entrevistados, a qualidade da terra, a qual se referem como "bonita", e a infraestrutura, conseguida pela luta da Crabi, fez com que eles "optassem" pelo reassentamento naquele local, pois realizaram muitas visitas a outras áreas antes de "escolherem" as terras que formaria Nova União.

A terra fértil e pouco acidentada permite que o proprietário possa cultivá-la quase que na totalidade, sendo este um dos fatores que motivaram a sua "escolha". É possível perceber o encantamento de P14 ao relatar que, "quando a gente viu essas terras, comparado ao lugar onde a gente morava, que era só morro e pedra, não tivemos dúvida, escolhemos o reassentamento".

Em relação à conquista da terra, Oliveira (2007) relaciona o preço da terra à sua produção, comparando terrenos mais ou menos férteis, com proximidades mais favoráveis ao escoamento da produção ou menos favoráveis (distância/custo de transporte). Segundo o autor (2007, p. 63):

O preço da terra no modo capitalista de produção (para os proprietários de terra e para os capitalistas) aparece, portanto, como juro do capital com que compra a terra e, por conseguinte, o direito à renda. Por isso, o preço da terra é regulado, de um lado, pelo montante da renda da terra e, de outro, pela taxa média de juro no mercado de capitais.

Esse preço da terra, informado pelos atingidos e apontado por eles mesmos como a conquista mais importante no contexto de lutas da Crabi, é descrito por Oliveira (2007), quando cita a renda da terra, usada para explicar o seu preço. O autor descreve a renda da terra como diferencial, quando essa é resultado da concorrência, e de renda absoluta, quando essa resulta do monopólio.

A renda da terra diferencial I apresenta fatores que distinguem uma região e outra, influenciando nos preços das terras. Para Oliveira (2007), as diferenças ficam evidentes quando, em áreas iguais, com aplicações de capitais iguais, produzem resultados desiguais. Os terrenos mais férteis, com os melhores solos, acabam privilegiados nesse processo, à medida que o mercado baliza pelos preços da produção dos piores terrenos, 
e isso faz com que os melhores terrenos levem uma vantagem natural.

Outro fator apontado como renda da terra diferencial I é a distância desta do local de venda, transformação ou exportação. Nesse caso, uma mesma produção, em áreas iguais e distâncias diferentes, influencia distintamente na renda da terra.

Porém, uma eficiência nos meios de transporte poderia corrigir essa distorção. Além disso, existe a premissa de que, quanto maior a distância do transporte, maior a redução do custo unitário. Mas, como o transporte é dependente de vários fatores, neste caso, prevaleceria, mesmo assim, o melhor solo.

Outro tipo de renda, chamado por Oliveira (2007) de renda diferencial II, resulta de altos investimentos, mesmo em terrenos férteis, tornando-os altamente produtivos. Diferencia-se da primeira (fertilidade do solo e localização), pois é uma causa estritamente capitalista, pois resulta de investimento de capital.

Existe ainda a renda terra absoluta, do monopólio, aquela em que os detentores da terra escolhem produzir ou não. Neste caso, diferentemente das rendas diferenciais I e II, é o resultado da mais-valia, em que o proprietário das terras somente irá produzir caso o preço do produto se eleve no mercado, ou seja, caso toda a sociedade colabore para o aumento dos lucros, e, para que esse lucro ocorra, os consumidores/trabalhadores precisam gerar mais-valia no mercado.

Contudo, a terra não é apenas um equivalente de mercadoria, pois possui também conteúdo subjetivo, o que é percebido no depoimento de P11, ao dizer: "Tenho saudade da antiga terra, dos amigos, nossos compadres que deixamos para trás", recordando a antiga propriedade que agora está embaixo d'água, em Nova Prata do Iguaçu, onde o lago de Salto Caxias se formou.

Os reassentados apontaram como conquista, além da terra, a infraestrutura.

Sobre infraestrutura, os resultados das entrevistas mostraram que os agricultores atualmente (2014) possuem trator, ensiladeiras, carretas de trator e outros equipamentos.

Verificou-se que as casas possuem instalações adequadas para cada família, com área construída acima de $70 \mathrm{~m}^{2}$, barracões para guarda de equipamentos e alguns como local de ordenha, verificou-se, ainda, que quase a totalidade das casas já sofreram alterações na estrutura (ampliação), aumentando a sua qualidade e conforto, demonstrando que os reassentados não apenas mantiveram suas conquistas, mas as ampliaram.

Além disso, quando questionados sobre a falta de algum equipamento para atender todo o ciclo produtivo, a grande maioria diz não ter colheitadeira, nem caminhão para o transporte e sendo que os demais equipamentos eles já possuem.

Ao retratarmos as diferenças entre o que possuíam antes do reassentamento (1997) e o que possuem atualmente (2014), verificaram-se importantes mudanças. 
Figura 7 - Infraestrutura: comparativo entre 1997 (antes do reassentamento) e 2014 (no reassentamento)

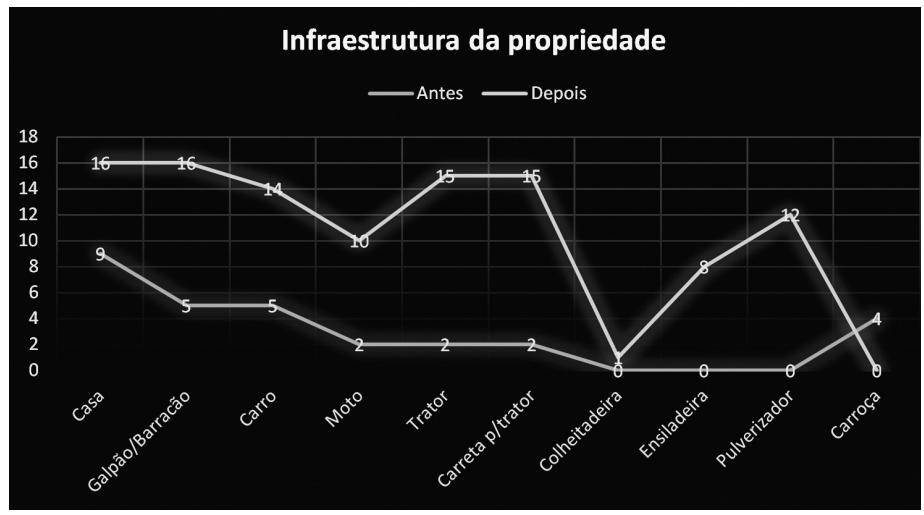

Fonte: Pesquisa de campo (2014).

Pode-se verificar que $44 \%$ dos entrevistados sequer tinham casa própria. P8 diz que "morava de favor, num cantinho que cederam pra eu poder criar meus sete filhos, nem a casinha de tábua rala não era minha" (informação verbal). Com exceção dos $25 \%$ proprietários, os $75 \%$ outros arrendatários (antes da usina) disseram não conseguir rendimento igual a um salário mínimo da época como rendimento mensal.

Nas palavras de P15, podem se verificar as situações pelas quais algumas famílias de atingidos passavam, antes do reassentamento, quando diz "Para quem não tinha nada antes do reassentamento, meu amigo, tudo o que aconteceu pra gente depois foi ganho".

Além das palavras dos reassentados, indicou-se que melhorias importantes aconteceram desde a mudança para a nova comunidade. Essas mudanças contribuíram para que esses atingidos permanecessem na atividade econômica da agricultura, contando com terreno próprio, casa, barracão e equipamentos necessários para desenvolver suas atividades.

Essas melhorias permitiram ainda que esses agricultores pudessem almejar alterações nas suas casas, construídas originalmente a partir de um modelo padrão acordado entre Crabi e Copel, passando por melhorias no barracão, nas estrebarias e na organização da área da propriedade.

Os entrevistados, porém, fazem questão de ressaltar que tudo foi conquistado com muita luta e pressão para indenizações. Por isso, segundo eles, o nome dado à nova comunidade carrega a marca do que foram aqueles momentos antes da mudança para a Nova União.

Durante as entrevistas, os reassentados enalteceram as conquistas que tiveram a partir das lutas, deixando as perdas serem percebidas nas entrelinhas. Quando questionados neste sentido, alguns relataram perdas em relação a laços familiares e de amizades, bruscamente interrompidos pela mudança para a nova comunidade. O reassentado P6 disse que "Agora todos temos carro, e qualquer coisa é só dar um pulinho, pois os parentes ficaram a pouco mais de cem quilômetros de distância". 
Embora não deixem transparecer que houve perdas, nas entrelinhas das entrevistas do trabalho de campo, percebe-se que elas aconteceram. Os laços de amizades, construídos ao longo do tempo e interrompidos pela mudança, são perdas que não são passíveis de indenizações. Assim, os reassentados tentam preencher esse vazio justificando que podem ver seus amigos a hora que quiserem, pois agora todos têm meio de transporte para fazê-lo. Contudo, mesmo sendo possível fazer isso, esquecem o custo do deslocamento, o deixar a propriedade e suas atividades, ou seja, o transtorno acaba se tornando um empecilho.

Já o reassentado P16 fez referência às humilhações que sofreram logo que mudaram para Cascavel. Segundo ele, "Os comerciantes de Cascavel achavam que nós éramos 'sem-terra' que haviam invadido uma fazenda. Sofremos com o preconceito no início, não foi fácil para pessoas honestas".

Talvez nem os próprios reassentados percebam, mas ter que restabelecer os laços de confiança com o comércio representa, também, uma perda. Aquela facilidade que se tinha, no antigo município, de negociar com os comerciantes locais, caso o dinheiro não fosse suficiente naquele momento, teve que ser todo refeito no novo município.

Em relação à atividade econômica desenvolvida nas novas propriedades, percebemos perdas significativas do ponto de vista da atividade de subsistência. Enquanto na antiga propriedade produziam arroz, feijão, milho, mandioca, batata doce, frutas, ou seja, produtos que permitiam ao agricultor buscar fora da propriedade apenas itens industrializados, na atual propriedade, perderam parte dessa característica, tornando-se mais dependentes do que se produz fora da propriedade. O entrevistado P6 disse que "Não temos horta na propriedade, é mais tranquilo comprar de fora, dá menos incômodo".

Ainda sobre essas perdas, o entrevistado P9 relatou: "Minha produção é de mais de mil litros de leite por dia, porém compro queijo no supermercado, não é viável fazer em casa".

Além disso, houve a venda de propriedades na comunidade Nova União. Esse fato foi confirmado pelos reassentados. O reassentado P1 declarou:

As vendas que aconteceram aqui, no meu ponto de vista, 'teve' a ver com as pessoas não conseguirem se encaixar na proposta que a comunidade tinha. Tinha que participar das reuniões, se ajudar. Algumas dessas pessoas não se sentiam confortáveis com isso. Além disso, teve gente que se envolveu com problemas na cidade, com 'mulherada', e aí sempre estavam pra cidade e a propriedade não se organiza sozinha.

Com essas informações sobre as vendas das propriedades, e na tentativa de compreender os motivos de tais vendas, questionamos os entrevistados sobre o problema, pois o paradeiro das pessoas que venderam suas propriedades é desconhecido pelos reassentados, e, ainda, foi relatado que houve o caso de suicídio de um ex-reassentado de Nova União.

Elaboramos, então, a partir de informações dos que ficaram, o Quadro 1, para expressar a opinião dos entrevistados sobre as causas das vendas de propriedades. 


\section{Quadro 1 - Motivos/causas das vendas de propriedades no reassentamento}

em Nova União

\begin{tabular}{|c|c|c|c|c|c|c|}
\hline & & \multicolumn{4}{|c|}{ As vendas de propriedades foram motivadas por: } & \multirow[b]{2}{*}{ Total } \\
\hline & & $\begin{array}{l}\text { Não se } \\
\text { acostumam } \\
\text { com o lugar }\end{array}$ & $\begin{array}{c}\text { Não tinham } \\
\text { habilidade para } \\
\text { lidar com a terra }\end{array}$ & $\begin{array}{c}\text { Não } \\
\text { souberam } \\
\text { administrar a } \\
\text { propiedade }\end{array}$ & $\begin{array}{c}\text { Eram } \\
\text { preguiçosos }\end{array}$ & \\
\hline \multirow{2}{*}{ 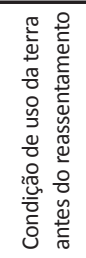 } & Propietários & $6,20 \%$ & $6,20 \%$ & $12,50 \%$ & & $25,00 \%$ \\
\hline & Arrendatários & $6,20 \%$ & $18,80 \%$ & $37,50 \%$ & $12,50 \%$ & $75,00 \%$ \\
\hline Total & & $12,50 \%$ & $25,00 \%$ & $50,00 \%$ & $12,50 \%$ & $100,00 \%$ \\
\hline
\end{tabular}

Fonte: Pesquisa de campo (2014).

Os reassentados que permanecem em Nova União e que, por ocasião da construção da usina, eram arrendatários, foram os que mais apontaram a incapacidade de administrar a propriedade como possível causa motivadora da venda de duas propriedades em Nova União.

A Copel poderia ter intervindo nessas questões, atuando como orientadora, a fim de evitar essas vendas. Essa incapacidade administrativa, apontada pelos próprios reassentados, seria passível de solução, com um acompanhamento adequado, pois se tratava de pessoas com baixa escolarização e suscetíveis de influências externas para poder comprar os terrenos. Com o acompanhamento devido, o destino desses agricultores poderia ser outro que não fosse o da venda dos terrenos.

Sobre a Copel, responsável pela construção da usina Salto Caxias, os entrevistados, na sua maioria, associam o nome da empresa ao sentimento de satisfação e ganho.

\section{Figura 8 - Sentimento dos reassentados em relação à Copel}

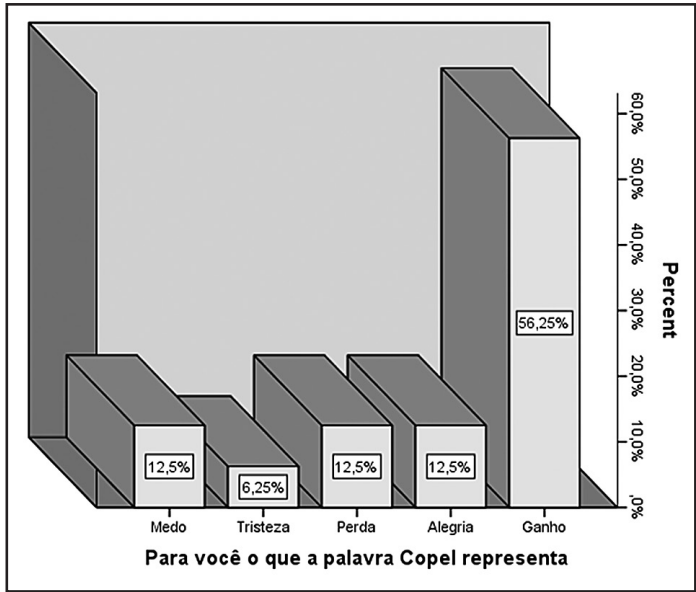

Fonte: Pesquisa de campo (2014). 
A palavra alegria, citada pelos reassentados, causou estranheza inicialmente. Mas, a partir da fala de P3, dizendo que "Essa construção da usina caiu do céu para nós, nunca mais uma dessa, foi como ganhar na loteria. Quando que ia imaginar ter minha terra para criar meus filhos" (informação verbal), ela se tornou mais clara.

Associarem o nome Copel às palavras ganho e alegria, como ocorreu na maioria das respostas, tendo sido expulsos da localidade onde moravam, torna-se compreensível à medida que a construção da usina Salto Caxias representou a possibilidade de adquirirem, pela primeira vez, um pedaço de terra própria, com casa, barracão, água encanada e, ainda, um salário mensal durante o primeiro ano na nova comunidade. Para $75 \%$ dos entrevistados, realmente foi uma mudança radical no estilo de vida passar de arrendatário para proprietário, num período de tempo muito além da expectativa dos mais otimistas. Assim, podemos perceber que adquirir o próprio pedaço de terra realmente tornou-se motivo de comemoração para esses atingidos.

As medidas dos lotes do reassentamento não apresentam muita dispersão, devido aos critérios adotados e acordados entre Crabi e Copel, mais uma das conquistas para os atingidos. A distribuição de terras no reassentamento baseou-se no critério de terreno mínimo de sete alqueires (incluindo a reserva), em que a área de reserva é comum para todos os reassentados. Além disso, a Crabi conseguiu incluir como conquista a "força de trabalho", que consistia em um acréscimo para as famílias que possuíam filhos, de forma a terem um tratamento diferenciado no quantitativo do terreno.

A força de trabalho foi definida no valor de dois alqueires e meio (2,5 alqueires) e os critérios de definições dos direitos foram descritos, para facilitar a compreensão de como se deram as medidas dos lotes que cada família atingida recebeu no reassentamento, principalmente no tocante à força de trabalho (Quadro 2).

\section{Quadro 2 - Percentual da força de trabalho na distribuição dos lotes do assentamento}

\begin{tabular}{|l|c|c|c|c|c|}
\hline $\begin{array}{l}\text { Idade dos } \\
\text { filhos }\end{array}$ & $\mathbf{0}$ até $\mathbf{5}$ anos & $\mathbf{5}$ até $\mathbf{1 0}$ anos & $\begin{array}{c}10 \text { até } \mathbf{1 5} \\
\text { anos }\end{array}$ & $\begin{array}{c}15 \text { até } 18 \\
\text { anos }\end{array}$ & $\begin{array}{c}\mathbf{1 8} \text { anos } \\
\text { ou mais }\end{array}$ \\
\hline $\begin{array}{l}\% \text { força de } \\
\text { trabalho }\end{array}$ & $0,0 \%$ & $25 \%$ & $50 \%$ & $75 \%$ & $100 \%$ \\
\hline
\end{tabular}

Fonte: Elaborado pelos autores (2014).

Esse critério da força de trabalho foi aceito pela Copel e, segundo os entrevistados, foi um bom critério, não provocando descontentamento entre os atingidos. De acordo com essas informações, é possível perceber que o objetivo da Crabi foi de fazer com que os terrenos não apresentassem discrepâncias, evitando, entre os atingidos, possíveis descontentamentos por um ou outro ser beneficiado ou prejudicado. Baseado nesses critérios acordados, as propriedades dos reassentados estão distribuídas conforme a próxima figura. 
Figura 9 - Área das propriedades dos entrevistados de Nova União

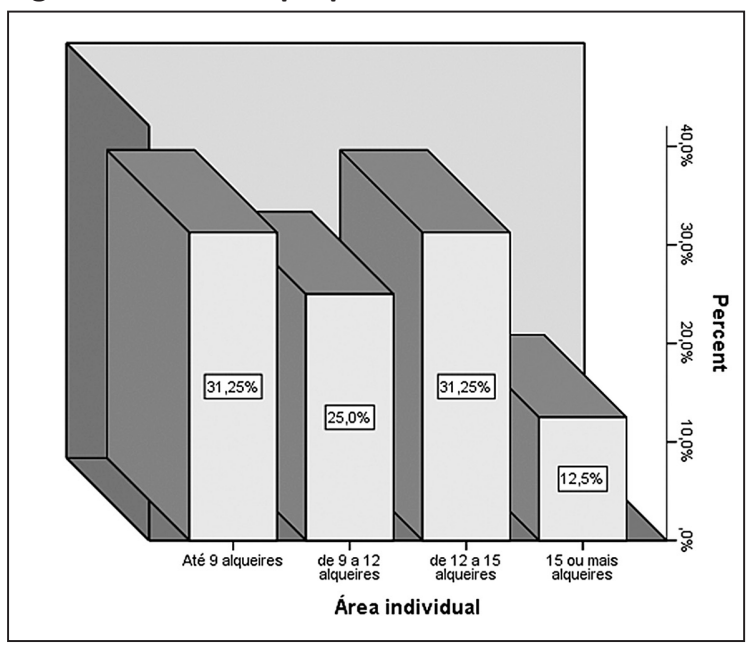

Fonte: Pesquisa de campo (2014).

Esta disposição gráfica anterior reforça a informação de que as propriedades dos reassentados não apresentam diferenças significativas em termos de área. Essa ideia de que as áreas de terras dos reassentados não apresentassem muita dispersão foi uma conquista da Crabi junto à Copel e funcionou como balisador entre os beneficiados, na tentativa de garantir direitos semelhantes para todos, bandeira erguida pelo movimento desde o início das lutas.

\section{Considerações finais}

Avaliar conquistas, num contexto de perdas, fez com que informações importantes sobre a realidade dos reassentados de Nova União fossem explicitadas. Ainda que os entrevistados tenham citado, entre essas conquistas, apenas a conquista da terra e da infraestrutura, nas entrelinhas das respostas obtidas, outras, também importantes, puderam ser evidenciadas

Verificamos, então, que houve conquistas no que se refere à terra, à infraestrutura, à ajuda às famílias, durante um ano, através do pagamento de uma quantia que variava de acordo com o tamanho dessa família, mas também houve perdas de laços afetivos (ligação com a terra, amigos e parentes) e comerciais, às quais não são previstas indenizações.

Portanto, houve conquistas e perdas, pois o processo indenizatório e o deslocamento de famílias para a construção de uma usina hidrelétrica é um processo contraditório. 


\section{Referências}

COPEL - COMPANHIA PARANAENSE DE ENERGIA. Disponível em: <http://www.copel. com/hpcopel/root/index.jsp>. Acesso em: 3 mar. 2014.

SEAB/DERAL - SECRETARIA DE ESTADO DA AGRICULTURA E DO ABASTECIMENTO/ DEPARTAMENTO DE ECONOMIA RURAL. Preços Anuais de Terras Agrícolas. 2014.

DERROSSO, Giuliano; ICHIKAWA, Elisa Yoshie. O papel da Crabi no assentamento dos ribeirinhos atingidos pela construção da hidrelétrica de Salto Caxias no estado do Paraná. Revista de Administração Pública (Impresso), v. 47, p. 133-155, 2013.

MAB. Coletivo de Educação do MAB: textos de aprofundamento e debate. Brasília: ANAB, 2008.

MARONI, João. Projeto águas do amanhã. Disponível em: <http://www.grpcom.com. $\mathrm{br} / \mathrm{grpcom} /$ projetos/projetos-aguas-do-amanha-alerta-sobre-poluicao-do-rio-iguacu. html>. Acesso em: 12 abr. 2014.

OLIVEIRA, Ariovaldo Umbelino. Modo de Produção Capitalista, Agricultura e Reforma Agrária. São Paulo: FFLCH, 2007.

RIBEIRO, Maria de Fátima Bento. Memórias do concreto: vozes na construção de Itaipu. Cascavel: Edunioeste, 2002.

SCHERER-WAREN. Ilse. Movimentos sociais no Brasil contemporâneo. História. Debates e tendências, v. 7, n. 1, p. 9-21, jan./jun. 2007. (Publ. 2o sem. 2008). 